\title{
УДК 65.015.2 \\ МЕТОДИЧЕСКИЕ ОСНОВЫ ПЛАНИРОВАНИЯ ТРУДОЕМКОСТИ \\ ИЗГОТОВЛЕНИЯ ТОВАРНОЙ ПРОДУКЦИИ \\ СУДОСТРОИТЕЛЬНЫХ ПРЕДПРИЯТИЙ
}

\author{
1Давыдовский Ф.Н., 2Величко Е.А. \\ 1 Северо - западный открытый технический университет, Санкт - Петербург, Россия \\ (195027 Россия, г. Санкт - Петербург, ул. Якорная, д. 9 A, литер A, a/я 177), e-таil: \\ Orion.6969@mail.ru \\ 2 ФГБОУ ВО «Санкт - Петербургский государственный университет. Колледж физической \\ культуры и спорта, экономики и технологии», Санкт-Петербург, Россия (198005 г. Санкт- \\ Петербург, Измайловский проспект, дом 27), е-тail: Ideaelena@yandex.ru
}

В статье рассмотрены вопросы, связанные с планированием трудоемкости изготовления товарной продукции и организацией нормирования трудовых процессо, используемых на судостроительных предприятиях. В ходе анализа действующих методов планирования трудоемкости, используемых на предприятиях отрасли, установлено, что на данный процесс в реальных условиях особое влияние оказывает высокий уровень дополнительной трудоемкости, следствием которого являются существенные отклонения фактических трудозатрат от технически обоснованных. Причинами возникающих отклонений, по нашему мнению, являются, прежде всего, неразвитые технологии изготовления, устаревший парк станочного оборудования, большой удельный вес брака, допущенного на стадиях промежуточных операций. Очевидно, что дополнительные трудозатраты на производство продукции должны учитываться при планировании и анализе причин отклонений. Однако, на практике дополнительная трудоемкость, как правило, не находит своего полного отражения при планировании трудозатрат, за счет чего и возникают существенные отклонения от технически обоснованного уровня трудоемкости изготовления продукции. Для преодоления данного недостатка планирования авторами предлагается использование норматива предельно допустимых отклонений фактической трудоемкости от плановой.

Ключевые слова: технологическая трудоемкость, дополнительная трудоемкость, планирование трудовых затрат.

\section{METHODICAL BASES OF PLANNING COMPLEXITY THE MANUFACTURE OF COMMERCIAL PRODUCTS SHIPYARDS}

\author{
1Davydovskii F.N., 2Velichko E.A.
}

1 North - Western Open Technical University, Saint - Petersburg, Russia (Russia 195027, Saint Petersburg, Anchor Street, 9 A, letter A, PO box 177), e-mail: Orion.6969@mail.ru

2 "Saint - Petersburg State University. College of Physical Education and Sport, Economy and Technology", St. Petersburg, Russia (198005, Saint Petersburg, Izmailovsky prospect, 27), e-mail: Ideaelena@yandex.ru

The article considers the issues related to planning the complexity of manufacturing products and the organization of regulation of labour processes used in shipyards. The analysis of existing methods of planning of labor input used in the industry, it was found that this process in real conditions a special influence of a high level of additional complexity, the consequence of which are significant deviations from the actual work technically sound. The reasons for occurring deviations, in our opinion, are underdeveloped manufacturing technology, outdated Park of machine tools, a large proportion of marriage made at intermediate stages of operations. Obviously, the additional labor costs of production should be considered when planning and analyzing causes of variances. However, in practice additional complexity, as a rule, finds its full reflection in the planning of labor costs, due to which there are significant deviations from the technically feasible level of complexity of manufacturing products. To overcome this lack of planning, the authors have proposed the use of the maximum permissible deviation of actual labor from planned.

Key words: technological complexity, additional complexity, planning for labor costs. 


\section{Введение}

В современной теории и практике научной организации труда важнейшим направлением развития является оптимизация планирования трудоемкости выпуска продукции с учетом реально сложившихся условий производства. Несмотря на это, низкий уровень производительности труда, необоснованно высокий уровень фактических трудозатрат, неэффективные технологии изготовления товарной продукции, характерные для ряда отраслей, по-прежнему остаются факторами неконкурентоспособности отечественной промышленности. Одним из таких факторов в судостроительной промышленности является система планирования трудоемкости выпуска, для которой характерно, по нашему мнению, недооценка влияния фактора возникновения дополнительной трудоемкости, возникающей вследствие отклонений в технологии изготовления товарной продукции. В целом ряде случаев величина таких отклонений достигает существенного уровня, непосредственно влияющего на рост трудозатрат в целом. Отсутствие же нормативно заданных величин подобных отклонений уже на стадии планирования трудоемкости, в свою очередь, не позволяет адекватно оценить причины роста производственных издержек и оперативно провести комплекс мероприятий по устранению дополнительной трудоемкости. Ее существование остается до сих пор объективным фактором отечественной промышленности, a, следовательно, ее необходимо учитывать при планировании и контроле трудовых затрат в ходе производственного процесса.

\section{§1. Материалы и методы исследования}

Предмет исследования: построение обоснованного плана трудоемкости изготовления товарной продукции на судостроительных предприятиях

Методы исследования: классификация причин отклонений фактической трудоемкости от плановой, нормативный метод расчета дополнительной трудоемкости на основе эмпирических данных динамики фактической трудоемкости.

Область применения: планирование и контроль динамики трудоемкости изготовления товарной продукции на предприятиях судостроения.

\section{Основание и исходные данные для разработки темы статьи}

Основаниями и исходными данными для написания статьи явились результаты выполнения научно - исследовательских работ, изложенных в соответствующих докладах и публикациях $[1,2,3]$.

\section{§2. Цели и задачи исследования}


1. Разработка и внедрение в реальную практику метода формирования и корректировки плана трудоемкости изготовления товарной продукции с учетом выявленных отклонений фактической трудоемкости от плановой.

2. Формирование перечня типовых причин (классификатора) отклонений фактической трудоемкости от плановой для проведения дальнейших корректировок с учетом дополнительной трудоемкости выпуска товарной продукции.

\section{§3. Результаты исследования и их обсуждение}

\section{Результаты}

- проанализированы состав и структура фактической трудоемкости выпуска товарной продукции на судостроительных предприятиях, выявлены недостатки планирования трудоемкости выпуска, связанные с недооценкой фактора влияния дополнительной трудоемкости на себестоимость товарной продукции судостроительных предприятий;

- сформирован перечень причин возникновения дополнительной трудоемкости выпуска, составивших соответствующий классификатор;

- предложена новая форма плана по трудоемкости выпуска товарной продукции с учетом дополнительной трудоемкости;

- предложен норматив предельно допустимых отклонений фактической трудоемкости выпуска от плановой в качестве средства выявления причин необоснованного роста трудозатрат в ходе производственного процесса.

\section{Обсуждение}

Сложившаяся методология исследования производительности труда в промышленности, рассматриваемая также авторами в ряде работ [1, 2,], направлена на комплексное решение следующих задач: измерение уровня производительности труда; изучение выполнения плана и динамики производительности труда; определение степени выполнения норм выработки рабочими; анализ уровня и динамики производительности труда - изучение факторов производительности труда и выявления резервов ее дальнейшего повышения; анализ взаимосвязи производительности труда с другими экономическими показателями, характеризующими результаты работы предприятия. Решение данного круга задач строится на том, что производительность труда определяется как эффективность затрат живого труда и рассчитывается через показатели выработки (В) и трудоемкости (Тр) продукции, между которыми имеется обратно пропорциональная зависимость. При этом выработка, рассчитываемая в нормо-часах, является основным показателем производительности труда, характеризующим количество (в натуральных показателях) или стоимость произведенной товарной продукции, приходящейся на единицу времени или одного среднесписочного работника. Соответственно, изменение производительности труда 
оценивается путем сопоставления выработки последующего и предшествующего периодов, т. е. фактической и плановой выработки. При этом превышение фактической выработки над плановой свидетельствует о росте производительности труда.

Выработка рассчитывается как отношение объема произведенной продукции (ОП) к затратам рабочего времени на производство этой продукции (Т) или к среднесписочной численности работников либо рабочих (Ч):

\section{$\mathrm{B}=\mathrm{OП} / \mathrm{T}$ или $\mathrm{B}=\mathrm{OП} / Ч$.}

Аналогично определяется часовая (Вч) и дневная (Вдн) выработка на одного рабочего:

$$
\text { Вч=ОПмес } / \text { Тчас; Вдн }=\text { ОПмес } / \text { Тдн, }
$$

где ОПмес - объем продукции за месяц (квартал, год); Тчас, Тдн - количество человекочасов, человеко-дней (рабочего времени), отработанных всеми рабочими за месяц (квартал, год).

Соответственно, объем произведенной продукции (ОП) может быть выражен в натуральных, стоимостных и трудовых единицах измерения. Трудоемкость продукции при этом выражает затраты рабочего времени на производство единицы продукции. Она определяется на единицу продукции в натуральном выражении по всей номенклатуре изделий и услуг. В свою очередь, при большом ассортименте продукции на предприятии, трудоемкость определяется по наиболее типичным изделиям, к которым приводятся все остальные. В отличие от показателя выработки этот показатель имеет ряд преимуществ: устанавливает прямую зависимость между объемом производства и трудовыми затратами, исключает влияние на показатель производительности труда изменений в объеме поставок по кооперации, организационной структуре производства, позволяет тесно увязать измерение производительности с выявлением резервов ее роста, сопоставить затраты труда на одинаковые изделия в разных цехах предприятия.

В зависимости от характера и назначения затрат труда, существуют следующие виды трудоемкости:

- нормативная (технологическая) трудоемкость - это время выполнения операции, рассчитанное на основе действующих норм времени по соответствующим технологическим операциям для изготовления единицы изделия или выполнения работы. Нормативная трудоемкость выражается в нормо-часах. Для перевода ее в фактические затраты времени она корректируется с помощью коэффициента выполнения норм, который увеличивается по мере роста квалификации рабочего;

- фактическая трудоемкость - это фактические затраты времени одного рабочего на выполнение технологической операции или изготовление единицы изделия в данный период; 
- плановая трудоемкость - это затраты времени одного рабочего на выполнение технологической операции или изготовление единицы изделия, утвержденные в плане и действующие в течение планового периода.

Величина трудоемкости изготовления продукции определяется по формуле:

$$
\mathrm{Tp}=\mathrm{T} / \mathrm{O},
$$

где Тр - трудоемкость, Т - время, затраченное на производство всей продукции, нормо-часов, человеко-часов, ОП - объем произведенной продукции в натуральном выражении.

В зависимости от состава затрат труда, включаемых в трудоемкость продукции, и их роли в процессе производства, выделяют технологическую трудоемкость, трудоемкость обслуживания производства, производственную трудоемкость, трудоемкость управления производством и полную трудоемкость.

Технологическая трудоемкость (Ттехн) отражает затраты труда основных производственных рабочих (Тсд) и рабочих-повременщиков (Тповр):

$$
\text { Ттехн }=\text { Тсд }+ \text { Тповр. }
$$

Трудоемкость обслуживания производства (Тобсл) представляет собой совокупность затрат вспомогательных рабочих цехов основного производства (Твспом) и всех рабочих вспомогательных цехов и служб (ремонтных, энергетических и т. д.), занятых обслуживанием производства (Твсп):

$$
\text { Тобсл }=\text { Твспом }+ \text { Твсп. }
$$

Производственная трудоемкость (Тпр) включает затраты труда всех рабочих, как основных, так и вспомогательных:

$$
\text { Тпр }=\text { Ттех }+ \text { Тобсл. }
$$

Трудоемкость управления производством (Ту) представляет собой затраты труда служащих (руководителей, специалистов и собственно служащих), занятых как в основных и вспомогательных цехах (Тсл.пр), так и в общезаводских службах предприятия (Тсл.зав):

$$
\text { Ту }=\text { Тсл.пр +Тсл.зав. }
$$

В составе полной трудоемкости (Тполн) отражаются затраты труда всех категорий промышленно-производственного персонала предприятия:

$$
\text { Тполн }=\text { Ттехн }+ \text { Тобсл }+ \text { Ту. }
$$

Таким образом, основными показателями расчета плановой трудоемкости изготовления продукции на предприятиях судостроения являются: технологическая трудоемкость, производственная трудоемкость, трудоемкость обслуживания производства и трудоемкость управления производством. Данные показатели определяют плановый уровень производительности труда посредством расчета плановой выработки. Отклонения от плановых значений данных показателей в сравнении с предельно допустимыми 
отклонениями в конечном итоге позволяют производить анализ «узких мест» организации труда на рабочих местах и выявить резервы роста эффективности производства.

Для формирования плановой трудоемкости принимается следующее положение:

$$
\text { Тполн.техн } \times \text { Ндоп. тр-ти }=\text { Тплан. }
$$

где: Ндоп. тр-ти - норматив дополнительной трудоемкости, \%

Тплан. - плановая трудоемкость товарной продукции, нормо-часы.

Полная технологическая трудоемкость, включаемая в план определяется по следующей формуле:

$$
\text { Т полн.техн }=\text { ПЗВ }+ \text { Ттехн. }
$$

где: ПЗВ - подготовительно-заключительное время на изготовление партии деталей, нормочасы.

Дополнительная трудоемкость - трудоемкость, обусловленная ходом производственного процесса и имеющая объективное техническое основание для включения в план. Причинами ее возникновения являются:

1. Несоответствие размеров и профиля заготовок или марки материалов предусмотренных техпроцессом, кроме заготовительных цехов или несвоевременная поставка заготовок и комплектующих изделий.

2. Дополнительные операции, не предусмотренные техпроцессом.

3. Переделка и переборка изделий при испытаниях.

4. Несоответствие оборудования, предусмотренного техпроцессом.

5. Исправление производственного брака, в том числе полученного по кооперации.

Перечисленные выше причины отклонений можно объединить в соответствующий классификатор, используемый для оценки влияния дополнительной трудоемкости.

Для включения в план дополнительной трудоемкости требуется определить ее удельное значение:

$$
\text { Тдоп. + Тм.п. = Тдоп. полн. }
$$

где: Тдоп. - чистая дополнительная трудоемкость, нормо-часы;

Тм.п. - трудоемкость малых партий, н*час нормо-часы;

Тдоп. полн. - полная дополнительная трудоемкость, нормо-часы.

Для включения в план используется только чистая дополнительная трудоемкость, поскольку наличие трудоемкости малых партий в условиях штучного и мелкосерийного производства не рассматривается.

Норматив дополнительной трудоемкости определяется эмпирическим методом и в условиях судостроительных предприятий составляет порядка $10 \%$ полной технологической трудоемкости (Ндоп. тр-ти $=0,1)$. 
Применение данного метода расчета является основой для составления плана по трудоемкости выпуска товарной продукции (таблица 1), исходя из расчета годовой производственной программы в нормо-часах. Для осуществления такого расчета необходимо

Таблица 1

План по трудоемкости выпуска товарной продукции

за месяц 20 года

\begin{tabular}{|c|c|c|c|c|c|c|c|}
\hline \multicolumn{4}{|c|}{$\begin{array}{c}\text { Фактическая трудоемкость выпуска } \\
\text { товарной продукции, н*час }\end{array}$} & \multicolumn{3}{|c|}{$\begin{array}{c}\text { Плановая трудоемкость } \\
\text { выпуска товарной } \\
\text { продукции, н*час }\end{array}$} & \multirow{2}{*}{ 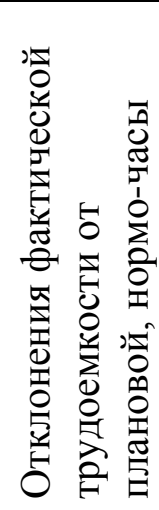 } \\
\hline 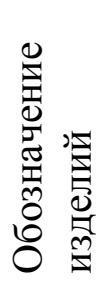 & 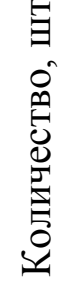 & 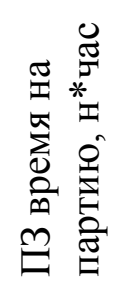 & 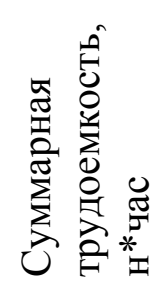 & 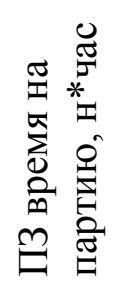 & 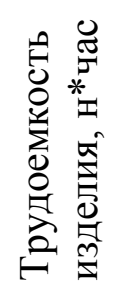 & 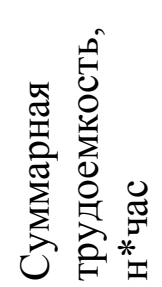 & \\
\hline Всего & & & & & & & \\
\hline
\end{tabular}

иметь разработанный номенклатурный план годового выпуска с разбивкой по месяцам и по видам производства (серия, доработка, сборка), данные о величине подготовительно заключительного времени на партию деталей, и о величине полученных отклонений.

Выявленные отклонения и предложенный классификатор причин их возникновения позволяют, во-первых, достаточно точно определить характер и источники роста дополнительной трудоемкости свыше нормативного уровня. Во-вторых, использовать различные способы организации контроля хода производства и причин возникновения брака на конкретных рабочих местах. В-третьих, постоянно корректировать план трудоемкости выпуска с учетом выявленных отклонений и реализации мероприятий по их устранению сверх нормативного уровня.

\section{§4. Заключение и выводы}

Представленные в статье результаты, позволяют сделать следующие выводы:

1. Действующая система планирования трудоемкости выпуска товарной продукции на судостроительных предприятиях недостаточно исчерпывающа, поскольку не учитывает фактор влияния на фактическую трудоемкость выпуска дополнительной трудоемкости, возникающей в силу целого комплекса причин, связанных как с использованием устаревших технологий и оборудования наряду с применением высокотехнологичного оборудования. 
2. Поскольку причины возникновения дополнительной трудоемкости имеют объективный характер, возникает необходимость ее учета при планировании. При изготовлении каждой единицы номенклатуры выпуска может возникать дополнительная трудоемкость, вызванная отклонениями реальных способов производства изделий от заданных технологических процессов. Данное явление остается неизбежным в силу преобладания на многих предприятиях устаревшего универсального оборудования и недостаточностью автоматизации производства.

3. С целью преодоления данного влияния предлагается в качестве средства контроля за фактической трудоемкостью использовать норматив ее предельно допустимых отклонений от плановых, сформированных на основе трудоемкости по технологическим процессам. Предложен соответствующий классификатор причин отклонений и эмпирически установлена величина данного норматива - не выше $10 \%$ технологической трудоемкости выпуска. Превышение фактической трудоемкости сверх данного норматива должно рассматриваться как источник возникновения не лимитированных затрат с реализацией комплекса мер технического и организационного характера.

\section{Список литературы}

1. Величко Е. А., Давыдовский Ф. Н. Классификация причин отклонений фактической трудоемкости от технологической как элемент планирования производительности труда машиностроительных предприятий [Текст] // Сборник статей Международной научнопрактической конференции «Прорывные научные исследования как двигатель науки». Самара. Часть 1. - Уфа: Научно - издательский центр «АЭТЕРНА». 2015. - С. 44 - 48

2. Величко Е. А., Давыдовский Ф. Н. Хозяйственная самостоятельность промышленных предприятий в условиях внутрифирменного расчета структурных звеньев энергетической монополии // Северо-Западный открытый технический университет. - С. 126 Депонированная рукопись. ВИНИТИ РАН. 26.08.2015 № 139-В2015

3. Давыдовский Ф.Н. Методические аспекты управления производительностью труда на судостроительных предприятиях Санкт-Петербурга [Электронная публикация] // Российское предпринимательство - М.: Издательство «Креативная экономика» - 2014. - №. 24 (270) - С. 62 - 70 - Режим доступа: http://bgscience.ru/lib/8760/

\section{Bibliography}

1. Velichko E.A., Davydovskii F.N. Klassifikacija prichin otklonenij fakticheskoj trudoemkosti ot tehnologicheskoj kak jelement planirovanija proizvoditel'nosti truda mashinostroitel'nyh predprijatij / «Proryvnye nauchnye issledovanija kak dvigatel' nauki»: sbornik statej Mezhdunarodnoj nauchnoprakticheskoj konferencii. Ufa, 2015, pp. $44-48$.

2. Velichko E.A., Davydovskii F.N. Hozjajstvennaja samostojatel'nost' promyshlennyh predpri-jatij v uslovijah vnutrifirmen-nogo rascheta strukturnyh zven'ev jenergeticheskoj monopolii / Northwest Open Technical University. - P. 126 - Deposited manuscript. VINITI. 26.8.2015 no. 139-V2015

3. Davydovskii F.N. Metodicheskie aspekty upravlenija proizvoditel'nost'ju truda na sudostroitel'nyh predprijatijah Sankt-Peterburga / Journal of Russian entrepreneurship, 2014, no. 24 (270), pp. 62 - 70. Available at: http://bgscience.ru/lib/8760/ 